\title{
Novel Partial Agonist of PPAR-Gamma for Treatment of Diabetic Neuropathy in Rats
}

Lídia M Lima ${ }^{1,2}$, Margarete M Trachez ${ }^{3}$, Josenildo Segundo Chaves de Araujo ${ }^{1}$, Jaqueline Soares da Silva ${ }^{1}$, Daniel Nascimento do Amaral ${ }^{1,2}$, Roberto T Sudo ${ }^{1}$, Eliezer J Barreiro ${ }^{1,2}$ and Gisele Zapata-Sudo ${ }^{1 *}$

${ }^{1}$ Programa de Desenvolvimento de Fármacos, Instituto de Ciências Biomédicas, Universidade Federal do Rio de Janeiro, Rio de Janeiro, RJ, Brazil

${ }^{2}$ Laboratório de Avaliação e Síntese de Substâncias Bioativas, Faculdade de Farmácia, Universidade Federal do Rio de Janeiro, Rio de Janeiro, RJ, Brazil

${ }^{3}$ Serviço de Anestesiologia, Universidade Federal Fluminense, Rio de Janeiro, RJ, Brazil

"Corresponding author: Gisele Zapata-Sudo, Universidade Federal do Rio de Janeiro, Centro de Ciencias da Saude, Instituto de Ciencias Biomedicas, Bloco J, Sala 14, Rio de Janeiro, RJ, Brazil, Tel: 21941-590; Fax: 55-21-25626505; E-mail: gsudo@icb.ufrj.br

Rec date: May 06, 2014, Acc date: June 18, 2014, Pub date: June 25, 2014

Copyright: ( 2014 Lima L M, et al. This is an open-access article distributed under the terms of the Creative Commons Attribution License, which permits unrestricted use, distribution, and reproduction in any medium, provided the original author and source are credited.

\begin{abstract}
This work describes a novel ligand for peroxisome proliferator-activated receptor gamma (PPARgamma) and its hypoglycemic and analgesic activity in a murine model of diabetes-induced neuropathic pain. The molecular recognition of LASSBio-1772 by a PPARgamma binding domain showed that the compound is a partial agonist. Four weeks after male Wistar rats received a single intravenous injection of streptozotocin (STZ, $60 \mathrm{mg} / \mathrm{kg}$ ), plasma glucose levels were increased from $92.5 \pm 3.7$ to $465.0 \pm 21.6 \mathrm{mg} / \mathrm{dL}(P<0.01)$ and serum insulin was reduced from $66.8 \pm 7.8$ to $25.5 \pm 5.6 \mathrm{pmol} / \mathrm{L}(\mathrm{P}<0.01)$. Diabetic animals were then, treated with either vehicle or LASSBio-1772 $(50 \mathrm{mg} / \mathrm{kg}$, i.p.) daily for 7 days. LASSBio-1772 significantly reduced blood glucose levels to $242.0 \pm 55.1 \mathrm{mg} / \mathrm{dL}$ $(\mathrm{P}<0.05)$ and increased insulin levels to $58.7 \pm 14.8 \mathrm{pmol} / \mathrm{L}(\mathrm{P}<0.05)$, indicating the hypoglycemic activity of this compound. LASSBio-1772 also reduced the elevated triglyceride levels induced by STZ treatment from $74.1 \pm 8.6$ to $34.0 \pm 6.3 \mathrm{mg} / \mathrm{dL}(\mathrm{P}<0.01)$. LASSBio-1772 could reduce serum glucose levels via increased insulin levels and potentially improve insulin sensitivity. Neuropathy was detected after four weeks of STZ-induced diabetes, with reduced thermal heat withdrawal latency from $11.7 \pm 0.1$ to $7.1 \pm 0.2 \mathrm{~s}(P<0.01)$ and paw withdrawal threshold from $37.5 \pm 2.1$ to $29.9 \pm 1.1 \mathrm{~g}(P<0.05)$ indicating the establishment of hyperalgesia and allodynia. LASSBio-1772 treatment restored both measures to non-diabetic values $(12.2 \pm 0.4 \mathrm{~s}$ and $34.5 \pm 1.5 \mathrm{~g})$. In conclusion, treatment with LASSBio-1772, a partial PPARgamma agonist, decreased hyperglycemia and neuropathic pain induced by diabetes. PPARgamma stimulation by LASSBio-1772 could prevent inflammation and inhibit both peripheral and central sensitization.
\end{abstract}

Keywords: PPAR-gamma; Diabetic neuropathy; LASSBio-1772; Streptozotocin

\section{Introduction}

Diabetes Mellitus (DM) is a prevalent, chronic, non-transmissible disease with high socioeconomic impact. The global occurrence of DM in adults aged 20 years and older in 2000 was estimated to be 171 million, with a projection of 383 million in 2030 [1-3]. Several serious complications can result from poorly controlled DM, including diabetic nephropathy, renal failure, blindness, and atherosclerotic vascular disease $[4,5]$. In addition, most patients with DM eventually develop neuropathy, with a lifetime risk of lower extremity amputations estimated in some populations to be up to $15 \%$. Hyperalgesia, paresthesias, and allodynia also occurs, with pain evident in $40-50 \%$ of those with diabetic neuropathy [6,7]. The substance most commonly used to induce DM in animal model is Streptozotocin (STZ) which can produce progressive death of beta cells. The intravenous dose used to simulates type $1 \mathrm{DM}$ in rats is 65 $\mathrm{mg} / \mathrm{kg}$ (four to five times less than which is lethal) can cause not only hyperglycemia but also peripheral neuropathy [8].

Peroxisome Proliferator-Activated Receptor (PPAR) is a subfamily of nuclear hormone receptors that regulate gene expression when activated [9]. The PPAR $\gamma$ isoform is expressed mostly in adipose tissue, and selective agonists, including thiazolidinedione derivatives such as rosiglitazone, pioglitazone, and troglitazone, are used clinically to treat DM [10,11]. Troglitazone causes hepatotoxicity but pioglitazone and rosiglitazone do not, suggesting that the toxicity is not related to PPAR $\gamma$ activation. PPAR $\gamma$ activation can regulate gene expression for genes involved in the metabolism of glucose and lipids, insulin sensitivity, cell growth, and differentiation [12,13]. PPAR $\gamma$ is also expressed in immune/inflammatory cells (e.g., monocytes and macrophages), which could contribute to its anti-inflammatory activity $[14,15]$. PPAR $\gamma$ ligands can reduce the expression of proinflammatory genes, decrease TNF- $\alpha$ production, and increase adiponectin expression.

Recently, Zapata-Sudo and coworkers described the compound 3'[(E)-[2-[(6-methyl-1,3-benzodioxol-5-yl)sulfonyl] hydrazinylidene] methyl]-benzoic acid, or LASSBio-1471, which had favorable theoretical affinity ( $\triangle$ Gbind) for PPAR $\gamma$ in docking studies. Administration of this compound $(20 \mathrm{mg} / \mathrm{kg}$, i.p, for 7 days $)$ improved oral glucose tolerance and reduced blood glucose levels in a murine STZ-induced diabetes model. LASSBio-1471 also showed analgesic effects in STZ-induced neuropathy, indicating potential as a novel hypoglycemic agent for pain relief in diabetic neuropathy [16]. To optimize this prototype, LASSBio-1471 was structurally modified using bioisosterism [17] and homologous strategies as shown in Figure 1. 
In the present study, we describe the design, synthesis, and evaluation of LASSBio-1772 in a model of diabetes-induced neuropathy. LASSBio-1772 - ((E)-N'-(4-cyanobenzylidene)-Nmethylbenzenesulfonyl-hydrazide) was obtained in good yields via the synthetic methodology previously described [16,18].

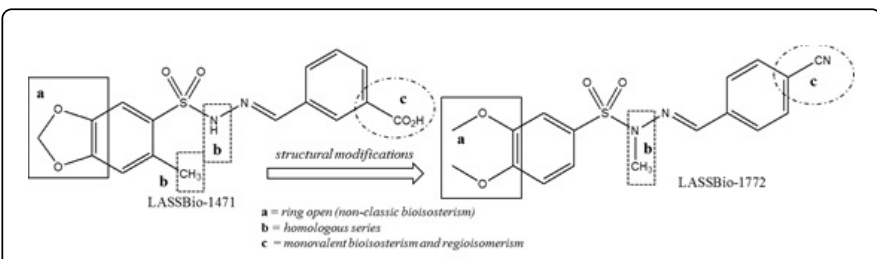

Figure 1: LASSBio-1772 - ((E)-N'-(4-cyanobenzylidene)-Nmethylbenzenesulfonyl-hydrazide) was obtained in good yields via the synthetic methodology

\section{Methods}

Synthesis and Characterization of E)-N'-(4cyanobenzylidene)- $\mathrm{N}$-methylbenzenesulfonylhydrazide (LASSBio-1772)

LASSBio-1772 was obtained in three linear steps using 3,4dimethoxybenzene-1-sulfonyl chloride as the commercial starting material, employing the methodology previously described by ZapataSudo et al. [11] and Kummerle et al. [15], as a pale yellow solid, m.p. $138^{\circ} \mathrm{C}$. The purity of LASSBio- 1772 was determined by HPLC using a Shimadzu - LC20AD apparatus, a Kromasil 100-5C18 (4,6 mm/6250 $\mathrm{mm}$ ) column, and the SPD-M20A detector (Diode Array) at $254 \mathrm{~nm}$ for quantification of analyte in a $1 \mathrm{~mL} / \mathrm{min}$ constant flux. The injector was programmed to inject a volume of $20 \mu \mathrm{L}$. The mobile phase used was $\mathrm{CH}_{3} \mathrm{CN}: \mathrm{H} 2 \mathrm{O}(6: 4){ }^{1} \mathrm{H}$ NMR (400 MHz, DMSO-d6) $\delta(\mathrm{ppm}) 7.90$ (d, 2H, J=8 Hz, H3'); 7.86 (s, 1H, N=CH); 7.83 (d, 2H, J = $\left.10 \mathrm{~Hz}, \mathrm{H} 2^{\prime}\right)$; 7.45 (d, 1H, J=10 Hz, H6); 7.28 (s, 1H, H2); 7.15 (d, 1H, J=8 Hz, H5); 3.81 (s, 3H, 4-OCH3); 3.77 (s, 3H, 3-OCH3); 3.21 (s, 3H, NCH3). ${ }^{13} \mathrm{C}$ NMR (50 MHz, DMSO-d6) $\delta$ (ppm) 153.0 (C4); 148.6 (C3); 141.5 $(\mathrm{C}=\mathrm{N}) ; 138.6\left(\mathrm{Cl}^{\prime}\right) ; 132.8\left(\mathrm{C}^{\prime}\right) ; 127.3\left(\mathrm{C} 2^{\prime}\right) ; 127.0(\mathrm{C} 1) ; 121.6(\mathrm{C} \equiv \mathrm{N})$; 118.6 (C6); 111.7 (C5); 111.3 (C4'); 110.1 (C2); 55.8 (4-OCH3); 55.8 (3-OCH3); 33.46 (NCH3). HPLC: $98.5 \%$ purity (R.T.=7.00; $\mathrm{CH}_{3}$ )

\section{Molecular modeling}

The compounds LASSBio-1471 and LASSBio-1772, both E diastereoisomers, were constructed and submitted for conformational analysis by molecular mechanics (MMFF method) with the Spartan 08' (Wavefunction Inc.; License number: DQAIR/HASPUSB). The carboxylic group of LASSBio-1471 was modeled in the ionization state at physiological $\mathrm{pH}$. The most stable conformer of each compound was re-optimized with the AM1 semi-empirical molecular orbital method [19] and saved as mol2 files for docking studies into the Ligand Binding Domain (LBD) of the PPAR- $\gamma$ crystallographic structure available in the Protein Data Bank (Code 1FM6; resolution: $2.10 \AA)[20]$.

The docking studies were implemented with the GOLD 5.1 program (CCDC; License number: G/414/2006) and the rosiglitazone structure was removed from the crystallographic structure (PDB code: 1FM6) to perform docking runs with the ChemPLP fitness function
[21] selected after the re-docking test. Data and poses were analyzed on the Pymol program (license number: 8588).

\section{Induction of experimental diabetes}

Male Wistar rats (180-220 g) received a single intravenous injection of streptozotocin (STZ, $60 \mathrm{mg} / \mathrm{kg}$ ) which was dissolved in citrate buffer ( $\mathrm{pH} 4.5)$ to induce diabetes. After 4 weeks, the STZ-treated rats were randomly divided into two groups ( $\mathrm{n}=6$ each) treated with vehicle (dimethylsulfoxide, DMSO) or LASSBio-1772 (50 mg/kg, i.p.). These groups were compared with a control group of normal rats (non-diabetic).

\section{Measurement of glucose, insulin, triglycerides and total cholesterol in plasma}

Plasma glucose levels were examined using the commercial kit, Accu-Check ${ }^{\circledast}$ Performa (Roche, Mannheim, Germany). Four weeks after the induction of diabetes with STZ, rats with glucose levels $>300$ $\mathrm{mg} / \mathrm{dL}$ were intraperitoneously injected with one dose of either vehicle or LASSBio-1772 daily for 7 days. Before and at the end of the treatment period with LASSBio-1772, plasma levels of glucose, insulin, total cholesterol, and triglycerides were measured in diabetic rats. Insulin, total cholesterol, and triglycerides were determined using colorimetric kits (Bioclin, MG, Brazil).

\section{Somatosensory testing - heat withdrawal and allodynia}

Heat withdrawal latency was assessed by applying radiant heat to the hind paw using a plantar analgesia meter (model 33, ITC Inc., CA, USA). Control latency was determined using the average response of three measurements separated by 5-min intervals. Mechanical allodynia was determined by the withdrawal threshold to pressure applied to the hind paw (in g) using a digital analgesimeter (model EFF301, Insight, SP, Brazil). Mechanical allodynia and thermal hyperalgesia were evaluated before and weekly after the STZ injection for 4 weeks, as well as 3 and 7 days after LASSBio-1772 treatment.

\section{Chemicals}

Streptozotocin and carrageenan were purchased from Sigma Chemical (St. Louis, MO, USA). LASSBio-1772 was synthesized and provided by Laboratório de Avaliação e Síntese de Substâncias Bioativas (UFRJ, Brazil). The compound was dissolved in dimethylsulfoxide (DMSO) (Merck, Darmstadt, Germany).

\section{Statistical Analysis}

Data were expressed as mean \pm S.E.M. and analyzed using the GraphPrism software (version 4.0). Comparison between nondiabetic, diabetic + vehicle (DMSO) and diabetic + LASSBio-1772 groups were analyzed using two-way ANOVA followed by the Bonferroni post-test. Differences between diabetic + vehicle (DMSO) and diabetic + LASSBio-1772 groups were determined using Student $\mathrm{t}$ test, with $\mathrm{P}<0.05$ considered significant for all tests.

\section{Results and Discussion}

\section{Molecular docking studies with PPAR $\gamma$}

As shown in Figure 1, rosiglitazone and LASSBio-1471 were able to interact by hydrogen bonding with Tyr473, His323, and Ser289 in the 
Citation: Lima L M, Trachez M M, de Araujo J S C,da Silva J S, do Amaral D N, et al. (2014) Novel Partial Agonist of PPAR-Gamma for Treatment of Diabetic Neuropathy in Rats. J Diabetes Metab 5: 392. doi:10.4172/2155-6156.1000392

Page 3 of 5

ligand binding domain of PPAR $\gamma$. The carboxylate anion (COO-) group of LASSBio-1471 interacted with the hydroxyl group of Tyr327 and Tyr473 and made a complementary interaction with His323 and Ser289. The 6-methyl-1,3-benzodioxol subunit shows hydrophobic interactions with Met364, Ile341, and Leu353 (Figure 2B). Those interactions are similar to the one produced by rosiglitazone involving the thiazolidine-2,4-dione unit with His323, His449, Ser289, and Tyr473. The hydrophobic interactions were ascribed to the N-methyl group of rosiglitazone, which interacts with Cys285, Leu353, and Met364 (Figure 2A). The interaction profile for rosiglitazone in the PPAR $\gamma$ binding domain is consistent with a previous report [22]. However, the new analog, LASSBio-1772, lost the electrostatic interaction with PPAR $\gamma$ and was unable to perform hydrogen bonding with the receptor. Nevertheless, it could produce a hydrophobic connection with Ile281, Ile341, Gly284, and Cys285 (Figure 2C). These differences in the molecular recognition of LASSBio-1772 by the PPAR $\gamma$ binding domain are represented in Figure 1D. These findings indicate a ligand profile different from a full PPAR $\gamma$ agonist (rosiglitazone-like) that lacks the hydrogen bond interactions with Tyr 473, His449, and His323, and seems more like the partial agonist, BVT13 [23].

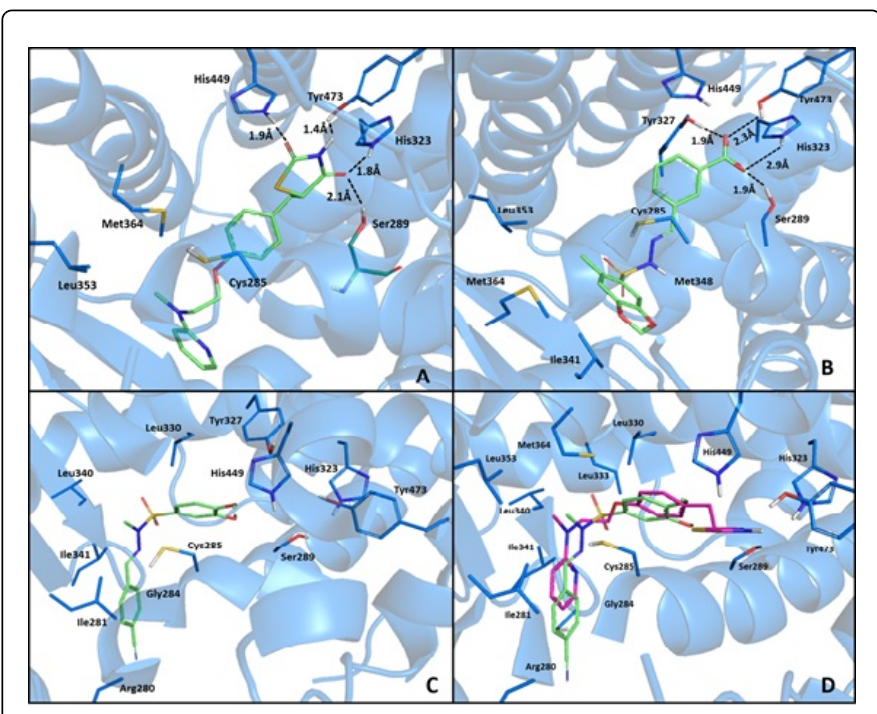

Figure 2: Interactions of rosiglitazone (A), LASSBio-1471 (B), and LASSBio-1772 (C) at the ligand binding domain of PPAR $\gamma$ (PDB code: 1FM6). Hydrogen bond interactions are shown as dotted lines. Superposition of rosiglitazone (pink) and LASSBio-1772 (light green) at the ligand binding domain of PPAR $\gamma(\mathrm{D})$

\section{Streptozotocin-induced diabetes in rats}

Four weeks after male Wistar rats received an intravenous injection of STZ to induce diabetes, the blood glucose concentration increased from $100.7 \pm 5.5$ to $512.6 \pm 34.7 \mathrm{mg} / \mathrm{dL}$. Serum glucose levels in rats treated with LASSBio- 1772 (50 mg/kg, i.p.) were reduced from $433.6 \pm$ $61.2 \mathrm{mg} / \mathrm{dL}$ before treatment to $242.4 \pm 55.3 \mathrm{mg} / \mathrm{dL} 7$ days after the beginning of treatment $(\mathrm{P}<0.05)$ (Figure $3 \mathrm{~A})$. Vehicle (DMSO) did not alter glucose levels which was $512.6 \pm 34.7$ and $410.0 \pm 58.0 \mathrm{mg} / \mathrm{dL}$ $(\mathrm{P}=0.16)$ before and after treatment, respectively. Daily LASSBio-1772 treatment significantly reduced blood glucose levels compared with vehicle-treated diabetic rats, indicating the hypoglycemic activity of this compound. In diabetic rats, insulin levels decreased from $67.1 \pm$
$7.7 \mathrm{pmol} / \mathrm{L}$ to $25.9 \pm 5.6 \mathrm{pmol} / \mathrm{L}$ and returned to $58.7 \pm 14.8 \mathrm{pmol} / \mathrm{L}$ $(\mathrm{P}<0.05)$ after 7 days of treatment with LASSBio-1772, indicating that STZ did not cause irreversible damage to the pancreatic islet cells and that LASSBio-1772 increased insulin release.

LASSBio-1772 could directly impact pancreatic -cells by reducing toxicity to the pancreatic islets via an unknown mechanism. Our hypothesis is that LASSBio-1772 may reduce pancreatic inflammation by decreasing the production of inflammatory mediators via activation of PPAR $\gamma$. In fact, PPAR $\gamma$ agonists such as LASSBio-1772 can impact cytokine production such as tumor necrosis factor a (TNFa) and interleukin-6 [24,25]. Both PPAR $\alpha$ and PPAR $\gamma$ receptors regulate inflammatory response [26], but the extent of this regulation and the mechanism are still controversial. LASSBio-1772 may increase insulin levels as well as improve insulin sensitivity via activation of PPAR $\gamma$ to reduce serum glucose levels. Insulin could increase glucose uptake by increasing the concentration of Glut 4 proteins. For example, PPAR $\gamma$ activation by rosiglitazone increased the expression and surface translocation of the glucose transporters, GLUT4 and GLUT1, thus increasing glucose uptake in adipocytes and muscle cells and reducing glucose plasma levels [27].

\section{LASSBio-1772 and lipid profile}

Diabetic rats showed a significant increase in triglyceride levels, from $49.4 \pm 3.5 \mathrm{mg} / \mathrm{dL}$ to $79.1 \pm 8.5 \mathrm{mg} / \mathrm{dL}$, and LASSBio- 1772 restored that dyslipidemia to $33.9 \pm 6.3 \mathrm{mg} / \mathrm{dL}$ (Figure $4 \mathrm{~A}$ ). There was no change in total cholesterol levels after the induction of diabetes, with levels $57.3 \pm 1.3 \mathrm{mg} / \mathrm{dl}$ before and $52.5 \pm 1.9 \mathrm{mg} / \mathrm{dL}$ ( $\mathrm{P}=0.13)$ after STZ administration. However, LASSBio-1772 treatment reduced cholesterol to $36.7 \pm 2.3 \mathrm{mg} / \mathrm{dL}$ (Figure $4 \mathrm{~B}$ ).

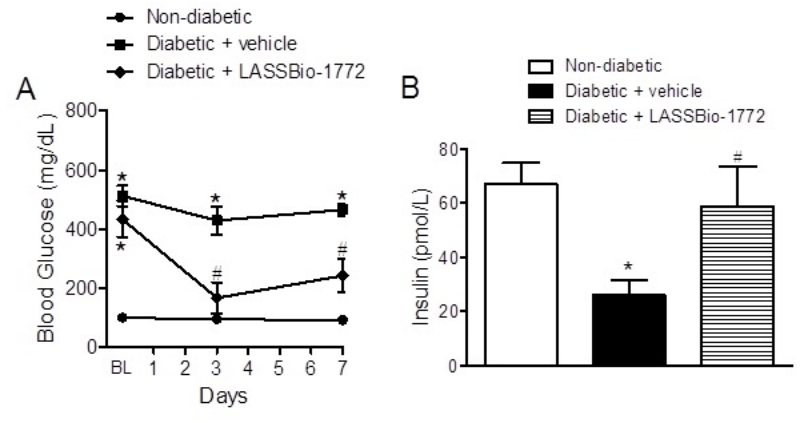

Figure 3: Changes in glucose (Panel A) and insulin levels (Panel B) at the end of the treatment of LASSBio-1772 in STZ-induced diabetes in rats. Values are expressed as mean \pm SEM. Student- $t$ test was used for comparison between diabetic + vehicle and diabetic + LASSBio-1772 groups. ${ }^{*} \mathrm{P}<0.05$ compared to non-diabetic group; $\# \mathrm{P}>0.05$ compared to diabetic + vehicle group, $\mathrm{n}=5$. $\mathrm{BL}$, baseline

LASSBio-1772 may improve lipid profiles in diabetic rats via increasing the lipolysis of circulating triglycerides, as reported for other PPAR $\gamma$ agonists [28]. 


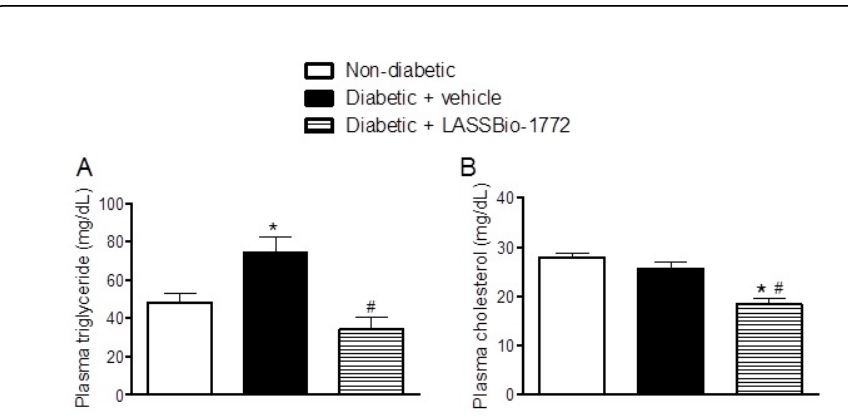

Figure 4: Effect of LASSBio-1772 administration on serum triglycerides and total cholesterol levels in STZ-induced diabetes in rats. Plasma triglyceride levels (Panel A) and cholesterol levels (Panel B) at the end of treatment. Values are expressed as mean \pm SEM. Student-t test was used for comparison between diabetic + vehicle and diabetic + LASSBio- 1772 groups. ${ }^{*} \mathrm{P}<0.05$ compared to non-diabetic group; $\# \mathrm{P}>0.05$ compared to diabetic + vehicle group, $\mathrm{n}=5$.

\section{Pancreatic sections after treatment with LASSBio-1772}

Histological evaluation was done in non-diabetic, diabetic animals treated or not with LASSBio-1772. Normal architecture of islet cells was observed in sections of pancreas of non-diabetic animals (Figure 5A). However, islets of Langerhans of diabetic group were dilated, degranulated and lost their arrangement of dense cords (Figure 5B). In contrast, diabetic rats treated with LASSBio-1772 partially restored the islets cells changes showing less damage and reduction in vacuolation (Figure 5C).

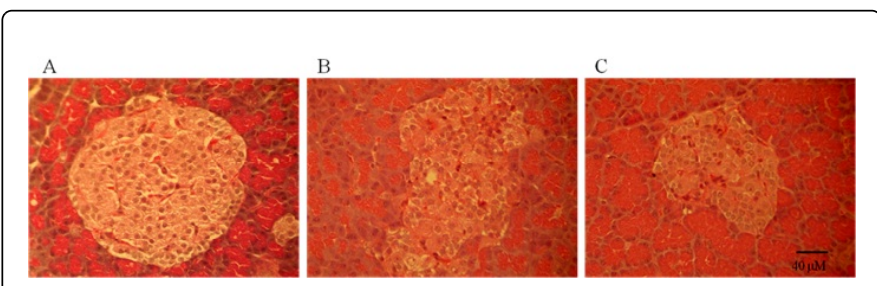

Figure 5: Histology of pancreatic islet of normal and diabetic rats stained with hematoxylin and eosin $(400 \times)$. (A) non-diabetic, (B) diabetic, (C) diabetic + LASSBio-1772 treatment

Diabetic rats treated with LASSBio-1772 showed less change in pancreas when compared to non-treated group indicating reduction of the degeneration observed after STZ-induced diabetes. The improvement of the architecture of pancreas induced by LASSBio-1772 could stimulate the secretion of insulin from the regenerated islet cells.

\section{LASSBio-1772 reduced pain induced by diabetic neuropathy}

Hyperalgesia, defined as decreased withdrawal latency, occurred 4 weeks after diabetes induction (Figure 6A), with change in withdrawal latency from $12.2 \pm 0.4 \mathrm{~s}$ to $7.1 \pm 0.1 \mathrm{~s}(\mathrm{P}<0.01)$ in the diabetic group. LASSBio- 1772 restored these latency values to $12.4 \pm 0.5 \mathrm{~s}$ after 7 days of treatment. Mechanical allodynia was evaluated using the paw withdrawal threshold test, and was significantly reduced from $39.2 \pm$ $0.9 \mathrm{~g}$ to $29.5 \pm 1.0 \mathrm{~g}$ in diabetic rats (Figure $6 \mathrm{~B}$ ).

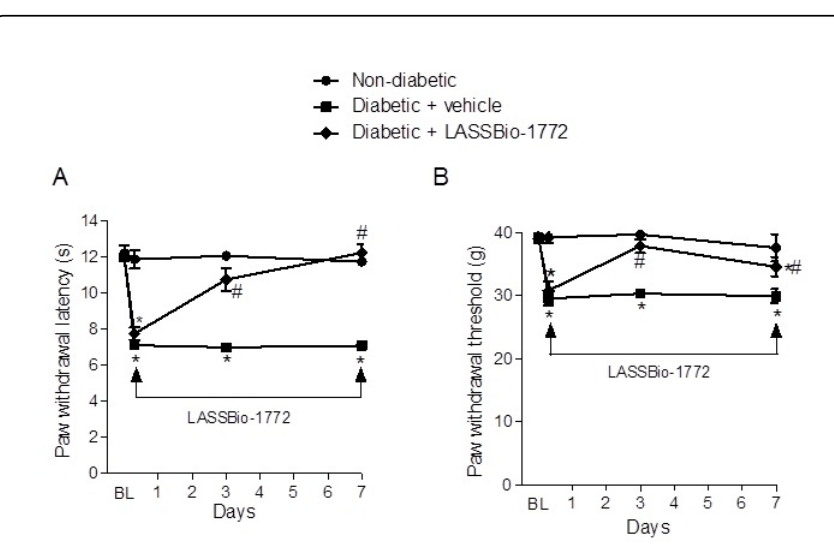

Figure 6: Effect of administration of LASSBio-1772 on diabetic neuropathy. Temporal changes in paw withdrawal latency (Panel A) and paw withdrawal threshold (Panel B) during 7 days of treatment. Values are expressed as mean \pm SEM. ANOVA one-way test followed by Dunnett post-tests or an ANOVA two-way test followed by Bonferroni were used for comparisons among groups. ${ }^{\star} \mathrm{P}<0.05$ compared to non-diabetic group; $\# \mathrm{P}>0.05$ compared to diabetic group, $\mathrm{n}=5$

Thus, animals in the STZ-induced diabetes group showed evidence of diabetic neuropathy 4 weeks after STZ treatment as evidenced by the appearance of both hyperalgesia and allodynia. LASSBio- 1772 significantly increased the paw withdrawal threshold from $30.8 \pm 1.1 \mathrm{~g}$ (before treatment initiation) to $34.5 \pm 1.5 \mathrm{~g}$ (Figure 4B), indicating alleviation of the allodynia response. LASSBio-1772 treatment also improved thermal hyperalgesia responses in diabetic animals.

Despite advances in the pharmacologic management of diabetesinduced neuropathic pain, treatment is not effective in all patients. Neuropathic pain observed after peripheral nerve injury, which can be subsequent to prolonged hyperglycemia, is associated with activated microglia in the dorsal horn of the spinal cord [27,28]. Activation of spinal microglia increases the production of pro-inflammatory cytokines, which increase spontaneous nociceptor activity [29]. $\operatorname{PPAR} \gamma$ stimulation promotes pain relief, which may be mediated by central sensitization through reduced activation of microglia [28]. Thus, PPAR $\gamma$ agonists such as pioglitazone and rosiglitazone prevent inflammation, which may underlie their neuroprotective mechanism as well. Additionally, these agonists decrease oxidative stress and inhibit nitric oxide generation via reducing the expression of nitric oxide synthase [30]. Therefore, PPAR $\gamma$ is an alternative target for diabetes-induced neuropathy that regulates lipid and glucose metabolism and suppresses inflammation in macrophages $[31,32]$ and microglia. Although the demonstration of the beneficial effects of LASSBio-1772 to reduce hyperglycemia and pain in STZ-induced diabetes, further studies are needed to identify possible side effects which could potentially limit its clinical use.

\section{Conclusions}

The new compound, LASSBio-1772, is a PPAR $\gamma$ ligand that restores glucose levels and improve lipid profile in diabetic rats. This partial 
agonist of PPAR $\gamma$ is a promising therapeutic candidate for the treatment of neuropathic pain that reduced thermal hyperalgesia and mechanical allodynia in a diabetic neuropathy model.

\section{Acknowledgement}

Funded by Coordenação de Aperfeiçoamento de Pessoal de Nível Superior (CAPES), Fundação Universitária Jose Bonifácio (FUJB), Instituto Nacional de Ciência e Tecnologia-Fármacos e Medicamentos (INCT-INOFAR), Fundação Carlos Chagas Filho de Amparo à Pesquisa do Estado do Rio de Janeiro (FAPERJ), Conselho Nacional de Desenvolvimento Científico e Tecnológico (CNPq).

\section{References}

1. Zimmet P (2002) Review: Epidemiology of diabetes - its history in the last 50 years. Brit J Diabetes Vasc Dis 2:435-439.

2. Wild S1, Roglic G, Green A, Sicree R, King H (2004) Global prevalence of diabetes: estimates for the year 2000 and projections for 2030. Diabetes Care 27: 1047-1053.

3. Freeman JS (2010) The increasing epidemiology of diabetes and review of current treatment algorithms. J Am Osteopath Assoc 110: eS2-6.

4. Brownlee M (2005) The pathobiology of diabetic complications: a unifying mechanism. Diabetes 54: 1615-1625.

5. Calcutt NA, Cooper ME, Kern TS, Schmidt AM (2009) Therapies for hyperglycaemia-induced diabetic complications: from animal models to clinical trials. Nat Rev Drug Discov 8: 417-429.

6. Forbes JM, Cooper ME (2013) Mechanisms of diabetic complications. Physiol Rev 93: 137-188.

7. Sadosky A, McDermott AM, Brandenburg NA, Strauss M (2008) A review of the epidemiology of painful diabetic peripheral neuropathy, postherpetic neuralgia, and less commonly studied neuropathic pain conditions. Pain Pract 8: 45-56.

8. Höke A (2012) Animal models of peripheral neuropathies. Neurotherapeutics 9: 262-269.

9. Zieleniak A, Wojcik M, Wozniak LA (2008) Structure and physiological functions of the human peroxisome proliferator-activated receptor gamma. Arch Immunol Ther Exp (Warsz) 56: 331-345.

10. Staels B, Fruchart JC (2005) Therapeutic roles of peroxisome proliferator-activated receptor agonists. Diabetes 54: 2460-2470.

11. Guilherme A, Virbasius JV, Puri V, Czech MP (2008) Adipocyte dysfunctions linking obesity to insulin resistance and type 2 diabetes. Nat Rev Mol Cell Biol 9: 367-377.

12. Escher P, Wahli W (2000) Peroxisome proliferator-activated receptors: insight into multiple cellular functions. Mutat Res 448: 121-138.

13. Corton JC, Anderson SP, Stauber A (2000) Central role of peroxisome proliferator-activated receptors in the actions of peroxisome proliferators. Annu Rev Pharmacol Toxicol 40: 491-518.

14. Jiang C, Ting AT, Seed B (1998) PPAR-gamma agonists inhibit production of monocyte inflammatory cytokines. Nature 391: 82-86.

15. Poynter ME, Daynes RA (1998) Peroxisome proliferatoractivated receptor $\mathrm{g}$ activation modulates cellular redox status, represses nuclear factor-kB signaling, and reduces inflammatory cytokine production in aging. J Biol Chem 273: 2833-32841.

16. Zapata-Sudo G, Lima LM, Pereira SL, Trachez MM, da Costa FP, et al. (2012) Docking, synthesis and anti-diabetic activity of novel sulfonylhydrazone derivatives designed as PPAR-gamma agonists. Curr Top Med Chem 12: 2037-2048.

17. Lima LM, Barreiro EJ (2005) Bioisosterism: a useful strategy for molecular modification and drug design. Curr Med Chem 12: 23-49.

18. Barco A, Benetti S, Pollini GP (1973) A facile alkylation of ethyl 2oxocyclopen-tanecarboxylate. Synthesis (Stuttg) 1973: 316-316.

19. Dewar MJS, Zoebisch EG, Healy EF, Stewart JJP (1985) The Development and Use of Quantum Mechanical Molecular Models .76. Am: a New General Purpose Quantum Mechanical Molecular Model. Journal of American Chemical Society, 107: 3902-3909.

20. Gampe RT Jr, Montana VG, Lambert MH, Miller AB, Bledsoe RK et al. (2000) Asymmetry in the PPARgamma/RXRalpha crystal structure reveals the molecular basis of heterodimerization among nuclear receptors. Mol Cel. 5: 545-555.

21. Korb O, Stützle T, Exner TE (2009) Empirical scoring functions for advanced protein-ligand docking with PLANTS. J Chem Inf Model 49: 84-96.

22. Latha RCR, Daisy P (2011) Insulin secretagogue, antihyperlipidemic and other protective effects of gallic acid isolated from Terminalia bellerica Roxb. In streptozotocin induced diabetic rats. Chem Biol Interact 189: 112-118.

23. Chandra V, Huang P, Hamuro Y, Raghuram S, Wang Y, et al. (2008) Structure of the intact PPAR-gamma-RXR- nuclear receptor complex on DNA. Nature 456: 350-356.

24. Östberg T, Svensson S, Selén G, Uppenberg J, Thor M et al. (2004) A New Class of Peroxisome Proliferator-activated Receptor Agonists with a Novel Binding Epitope Shows Antidiabetic Effects. J Biol Chem 279: 41124-41130.

25. Monsalve FA, Pyarasani RD, Delgado-Lopez F, Moore-Carrasco R (2013) Peroxisome proliferator-activated receptor targets for the treatment of metabolic diseases. Mediators Inflamm 2013: 549627.

26. Gamaro GD, Suyenaga E, Borsoi M, Lermen J, Pereira P, et al. (2011) Effect of rosmarinic and caffeic acids on inflammatory and nociception process in rats. ISRN Pharmacol 2011: 451682.

27. Cuzzocrea S, Pisano B, Dugo L, Ianaro A, Maffia P, et al. (2004) Rosiglitazone, a ligand of the peroxisome proliferator-activated receptorgamma, reduces acute inflammation. Eur J Pharmacol 483: 79-93.

28. Faveeuw C, Fougeray S, Angeli V, Fontaine J, Chinetti G, et al. (2000) Peroxisome proliferator-activated receptor gamma activators inhibit interleukin-12 production in murine dendritic cells. FEBS Lett 486: 261-266.

29. Iwai S, Maeda T, Kiguchi N, Kobayashi Y, Fukazawa Y, et al. (2008) Pioglitazone attenuates tactile allodynia and microglial activation in mice with peripheral nerve injury. Drug Discov Ther 2: 353-356.

30. Tsuda M, Inoue K, Salter MW (2005) Neuropathic pain and spinal microglia: a big problem from molecules in "small" glia. Trends Neurosci 28: 101-107.

31. Xing B, Xin T, Hunter RL, Bing G (2008) Pioglitazone inhibition of lipopolysaccharide-induced nitric oxide synthase is associated with altered activity of p38 MAP kinase and PI3K/Akt. J Neuroinflammation 5: 4 .

32. Straus DS, Glass CK (2007) Anti-inflammatory actions of PPAR ligands: new insights on cellular and molecular mechanisms. Trends Immunol 28: 551-558. 